\title{
Successful Treatment of Post-operative Keloid with Combined Cryotherapy and Ablative Fractional $\mathrm{CO}_{2}$ Laser
}

\author{
Jihee $\operatorname{Kim}^{1,2,3}$ \\ Young In Lee ${ }^{1,2}$ \\ Ju Hee Lee ${ }^{1,2}$ \\ Sang $\mathrm{Ho} \mathrm{Oh}^{1}$ \\ Sang Eun Lee ${ }^{1}$ \\ Young Koo Kim ${ }^{4}$
}

\footnotetext{
${ }^{1}$ Department of Dermatology, Yonsei University College of Medicine, Seoul, Korea

${ }^{2}$ Scar Laser and Plastic Surgery Center, Yonsei Cancer Hospital, Seoul, Korea

${ }^{3}$ Department of Dermatology, Yongin Severance Hospital, Yongin, Korea

${ }^{4}$ Yonsei Star Skin \& Laser Clinic, Seoul, Korea
}

\begin{abstract}
Keloids are pathologic fibroproliferative conditions characterized by excessive collagen deposition during wound healing. The pathogenesis of keloids is not fully understood, and current treatment options show variable results. In this case report, the patient developed a keloid after bilateral total thyroidectomy, and was treated with a combination approach using fractional ablative laser systems along with cryotherapy and triamcinolone injection. After seven monthly sessions of combination treatment, the patient presented marked improvement of the scar texture and symptoms. Furthermore, there was no recurrence for up to 2 years. We propose this combination as a safe and effective treatment option for keloid patients.
\end{abstract}

\section{Key words}

Keloid; Scar; Fractional laser

\section{Correspondence}

Young Koo Kim

Yonsei Star Skin \& Laser Clinic, 73 Sinchon-ro,

Seodaemun-gu, Seoul 03789, Korea

Tel.: +82-33-741-1384

Fax: +82-33-748-2650

E-mail: yonseistar64dhanmail.net

(C) Korean Society for Laser Medicine and Surgery

(c) This is an open access article distributed under the terms of the Creative Commons Attribution NonCommercial License (http://creativecommons.org/ licenses/by-nc/4.0) which permits unrestricted noncommercial use, distribution, and reproduction in any medium, provided the original work is properly cited. 


\section{INTRODUCTION}

Optimal wound healing requires a well-orchestrated integration of biological and molecular events regulating cell migration, proliferation, and extracellular matrix (ECM) remodelling. ' Keloids are a pathologic fibroproliferative condition characterized by excessive collagen deposition during the wound healing. ${ }^{1,2}$ Numerous treatment options have been suggested; cryotherapy, intralesional injection, and laser treatment. Nonetheless, keloid treatment remains a challenging condition, and current treatment options still have limitations. ${ }^{1,3}$ Better understanding into the pathogenesis with allow for the development of newer and more targeted treatment.

Nowadays, combination approaches using multiple laser modalities have shown successful treatment outcome of hypertrophic scars and keloids. ${ }^{4,5}$ Combining cryotherapy along with fractional and non-fractional laser showed good response in many patients. ${ }^{3,6}$

Herein, we report a case of keloid patient treated with combination treatment using fractional ablative lasers systems along with cryotherapy and triamcinolone injec- tion. After monthly seven sessions of combination treatment, the patient presented marked improvement on the scar texture and symptoms with no remarkable side effects or recurrence over two years.

\section{CASE REPORT}

A 21 -year-old Korean woman visited the clinic with a keloid on the post-thyroidectomy site. The patient underwent a bilateral total thyroidectomy due to thyroid adenocarcinoma six months ago. A well-demarcated erythematous firm mass was noted on the patient's anterior neck between the clavicles (Fig. 1A and B). The patient presented with pain and pruritus on the keloid and tenderness due to traction of the skin.

After obtaining informed consent, topical anaesthetic agent EMLA ${ }^{\circledR}$ cream leutectic mixture of $2.5 \%$ lidocaine $\mathrm{HCl}$ and 2.5\% prilocaine; AstraZeneca AB, Sodertalje, Sweden) was applied under occlusion 30 minutes before the treatment. The patient was treated with $10,600 \mathrm{~nm}$ ablative fractional $\mathrm{CO}_{2}$ laser using $\mathrm{eCO}^{\mathrm{TM}}$ laser (Lutronic Corporation, Goyang, Korea). Immediately after, superfi-
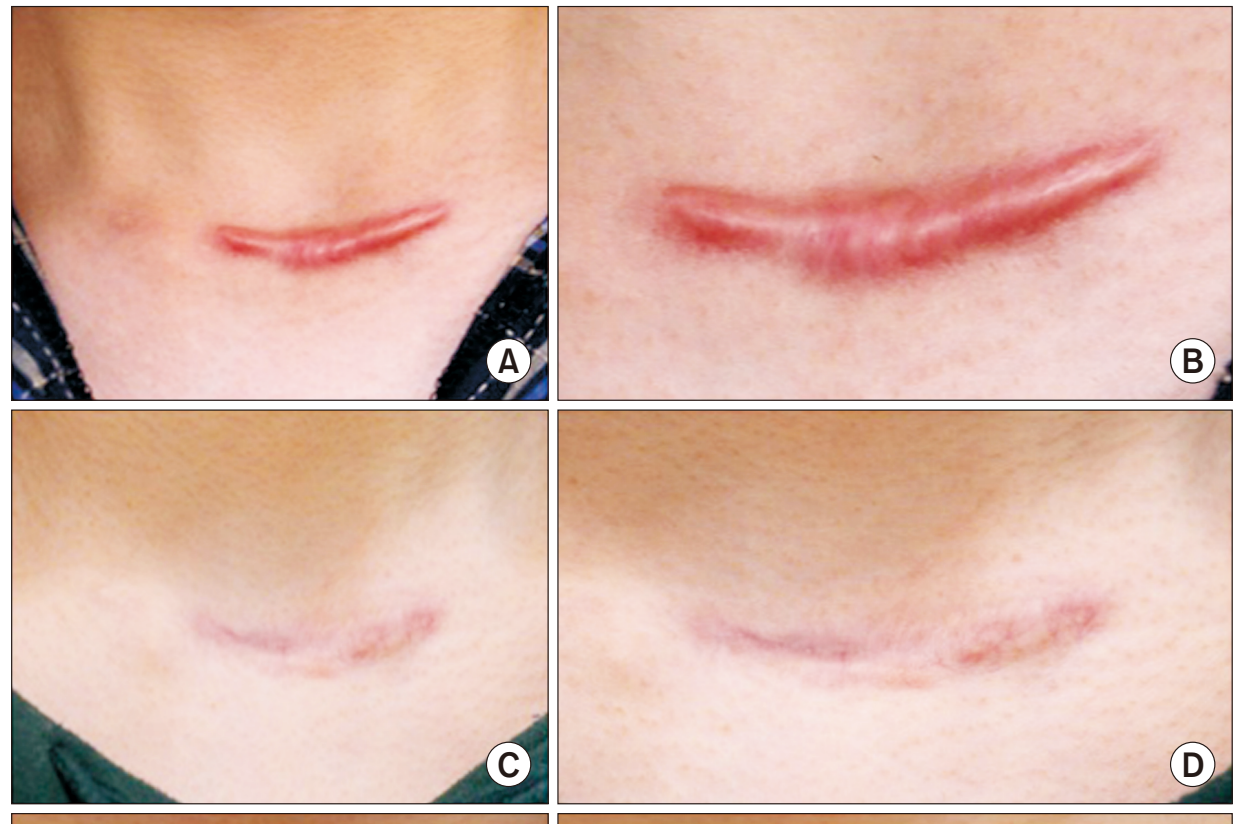

Fig. 1. (A, B) A keloid scar on the anterior neck of the patient. (C, D) After five sessions of combination treatment with fractional ablative $\mathrm{CO}_{2}$ laser followed by cryotherapy and triamcinolone injection. $(\mathrm{E}, \mathrm{F})$ Two year after the initial visit. The patient did not show recurrence on the treated lesion. 
cial cryotherapy (CryopPen ${ }^{\circledR}$, CryoPen Inc., Texas, USA) was performed on the laser-irradiated site until achieving superficial frosting. A freeze-thaw cycle of ten seconds was performed for two cycles. Lastly, intra-lesional injection of triamcinolone $10 \mathrm{mg} / \mathrm{mL}$ was done. The combination treatment was performed for five session $\mathrm{s}$ in a monthly follow-up visit.

After six months, the patient showed telangiectasia on the treated lesions with a visible reduction of the keloid volume (Fig. 1C and D). The patient was treated with a pulsed-dye laser using Regenlite ${ }^{T M}$ (Chromogenix, Swansea, UK) for two additional sessions and instructed to use silicone sheet $\left(\mathrm{MegaHeal}^{\circledR}\right.$, L\&C Bio, Seoul, Korea) for at least six hours every day. After nine months, the patient showed marked improvement in scar texture. During the follow-up period for two years, the patient did not show additional pain or pruritus without worsening or recurrence (Fig. 1E and F).

\section{DISCUSSION}

Various treatment options have been suggested for keloid, yet no single modality is known to be fully effective. In most clinical settings, intralesional triamcinolone injection remains the first-line therapy for the treatment keloids. ${ }^{6.7}$ However, monotherapy with triamcinolone may cause frequent recurrence and high rates of potential adverse effects, including skin atrophy, hypopigmentation, and telangiectasia. Therefore, the recent advance in clinical studies of scar treatment recommends a combinational approach over monotherapy. ${ }^{3,4,8}$

The addition of cryotherapy with triamcinolone injection leads to more rapid response leading to the early flattening of the lesions due to microvascular damage. ${ }^{4,7}$ Fractional ablative $\mathrm{CO}_{2}$ laser systems are commonly used for drug-delivery by creating micro-channels deep into the dermis. The use of topical triamcinolone or steroidbased preparations after fractional $\mathrm{CO}_{2}$ lasers have shown a beneficial effect in a hypertrophic scar or keloid treatment. ${ }^{7}$ Recently, our group have reported a retrospective review on the effect of combination treatment on various types of keloid scars. We believe the addition of fractional $\mathrm{CO}_{2}$ laser to the combination of cryotherapy and intralesional TA injection may enhance effective delivery of triamcinolone to the entire areas of the firm lesions of a keloid scar. ${ }^{7,9}$ Additionally, we used pulsed dye laser system to target post-treatment telangiectasia on the current patient. Pulsed dye laser systems are known to improve the erythema and vascular component of keloid scars by improving the pliability of the lesion., ${ }^{3,10}$
Despite decades of research, scar treatment remains a challenging condition, and current treatment options still have limitations-better understanding into the pathogenesis with allowing for the development of newer and more targeted treatment in the future.

The authors suggest that a multimodal approach can be applied to target various pathogenic factors in keloid scars. And we demonstrated that the combination usage of multiple lasers, superficial cryotherapy, and intralesional triamcinolone injection is safe and effective for keloid patient. Further prospective, controlled investigations are needed to compare the efficacy of combination treatment and suggest the optimal treatment parameters for keloid scars.

\section{CONFLICT OF INTEREST}

The authors declare no conflicts of interest.

\section{REFERENCES}

1. Gauglitz GG, Korting HC, Pavicic T, Ruzicka T, Jeschke MG. Hypertrophic scarring and keloids: pathomechanisms and current and emerging treatment strategies. Mol Med 2011;17:11325.

2. Kim J, Kim B, Kim SM, Yang CE, Song SY, Lee WJ, et al. Hypoxia-induced epithelial-to-mesenchymal transition mediates fibroblast abnormalities via ERK activation in cutaneous wound healing. Int J Mol Sci 2019;20:2546.

3. Lee YI, Kim J, Yang CE, Hong JW, Lee WJ, Lee JH. Combined therapeutic strategies for keloid treatment. Dermatol Surg 2019;45:802-10.

4. Yosipovitch G, Widijanti Sugeng M, Goon A, Chan YH, Goh CL. A comparison of the combined effect of cryotherapy and corticosteroid injections versus corticosteroids and cryotherapy alone on keloids: a controlled study. J Dermatolog Treat 2001;12:8790.

5. Darougheh A, Asilian A, Shariati F. Intralesional triamcinolone alone or in combination with 5-fluorouracil for the treatment of keloid and hypertrophic scars. Clin Exp Dermatol 2009;34:21923.

6. van Leeuwen MC, Bulstra AE, Ket JC, Ritt MJ, van Leeuwen PA, Niessen FB. Intralesional cryotherapy for the treatment of keloid scars: evaluating effectiveness. Plast Reconstr Surg Glob Open 2015;3:e437.

7. Behera B, Kumari R, Thappa DM, Malathi M. Therapeutic efficacy of intralesional steroid with carbon dioxide laser versus with cryotherapy in treatment of keloids: a randomized controlled trial. Dermatol Surg 2016;42:1188-98.

8. Khan MA, Bashir MM, Khan FA. Intralesional triamcinolone 
alone and in combination with 5-fluorouracil for the treatment of keloid and hypertrophic scars. J Pak Med Assoc 2014;64:1003-7.

9. Park JH, Chun JY, Lee JH. Laser-assisted topical corticosteroid delivery for the treatment of keloids. Lasers Med Sci 2017;32:601-8.

10. Park KY, Hyun MY, Moon NJ, Jeong SY, Seo SJ, Hong CK. Combined treatment with 595-nm pulsed dye laser and 1550-nm erbium-glass fractional laser for traumatic scars. J Cosmet Laser Ther 2016;18:387-8.
How to cite this article: Kim J, Lee YI, Lee JH, Oh SH, Lee SE, Kim YK. Successful treatment of post-operative keloid with combined cryotherapy and ablative fractional $\mathrm{CO}_{2}$ laser. Med Lasers 2020;9:58-61. https://doi.org/10.25289/ ML.2020.9.1.58 